\title{
COMPLEXITY, CONNECTANCE AND LINK DENSITY IN CONTINENTAL FOOD WEBS: DISSIMILARITIES IN AQUATIC AND TERRESTRIAL FOOD WEBS AND THEIR HABITATS
}

\author{
VITEKERE, K. ${ }^{1,2}-$ HUA, Y. $.^{*}-$ JIANG, G. ${ }^{1^{*}}$ \\ ${ }^{1}$ Feline Research Center of National Forestry and Grassland Administration, College of \\ Wildlife and Natural Protected Areas, Northeast Forestry University, Harbin 150040, China \\ ${ }^{2}$ Tayna Center for Conservation Biology, University of Nature Conservation and Development \\ at Kasugho, Goma 167, North-Kivu, Democratic Republic of Congo \\ ${ }^{3}$ Guangdong Provincial Key Laboratory of Silviculture, Protection and Utilization, Guangdong \\ Academy of Forestry, Guangzhou 510520, China \\ ${ }^{*}$ Corresponding authors \\ e-mails:wildlife530@hotmail.com and jgshun@126.com \\ (Received $10^{\text {th }}$ Aug 2020; accepted $22^{\text {nd }}$ Oct 2020)
}

\begin{abstract}
Both terrestrial and aquatic food webs are characterized by similar key parameters: connectance, robustness, and linkage. Ecosystems vary in basic structures and by processes that govern their dynamics and complexity. A study of complexity, connectance and link density in terrestrial and aquatic food webs, was conducted. We used 49 food webs apportioned in 23 terrestrials, 15 lacustrine and 11 rivers. The results revealed that aquatic food webs presented a difference in superiority of average connectance and link density, $(p \sim 0.05)$, depicting an absence of differences in means. A regression test revealed that connectance and link density are inversely correlated in terrestrial food webs and contrary in other habitats, which was the same case for connectance and the average length of chain. We assume that connectance should be positively correlated with other parameters (fluxes and interaction strengths) in terrestrial habitat as its variations were not explained by link density or the average length of chain. This study revealed a higher estimate of connectance in aquatic habitats compared to their terrestrial counterparts. Aquatic habitats are potentially characterized by high values of parameters related to the connection (interactions quality, organisms' growth, and food web size) while terrestrial ones are more branded by features depicting constancy (productivity, complexity, and diversity).
\end{abstract}

Keywords: average length chain, ecosystems, interactions, stability, terrestrial, lacustrine, rivers

\section{Introduction}

It is largely known that complex structures such as ecosystems or societies are empirically simplified into three principal aspects: quality, quantity, and stability (Worm and Duffy, 2003). In ecosystems, quality refers to species richness, quantity to biomass or production of living matter and stability to resilience capacity (McCann, 2012). There is interdependence among a wide range of ecological network properties (Vermaat et al., 2009; Gravel et al., 2011). Organisms always interact within habitats when they are linked by feeding behaviour or habit. Interconnected species by such links constitute a food web which are networks of who eats whom within an ecosystem (Cohen et al., 1990; Canning and Death, 2017).

Most ecologists are concerned about biodiversity loss due to human threats on natural habitats (Gilbert, 2009; Bolchoun et al., 2017), but less attention has been given on the imbalance from the destabilization of food web complexity and interactions in an ecosystem (McCann, 2000; Worm and Duffy, 2003; Hagen et al., 2012), and these facts 
have often been neglected based on the debated opinion that such imbalances take place on much longer time scales (Koch et al., 2014). Naturally, species conservation should imply protection of complex interactions in ecosystem since these interactions networks express essential patterns in species coexistence within habitats (Montoya et al., 2006; Bascompte and Jordano, 2007). This assumption stipulates that the complexity characteristics of species interactions, mostly measured by network connection, are an interesting feature of fit communities that generally protects them from diverse destabilizations (Polis, 1991). Unfortunately, the previous overview indicates that conservation efforts were not implemented to the protection of strongly connected communities but were focused on one species' conservation patterns (Boogert et al., 2006; Tylianakis et al., 2010; Heleno et al., 2012; Jordano, 2016). Thus connectance, a useful parameter in understanding dynamics of a food web is one of the most basic and standard metrics to characterize species interaction (Gilbert, 2009; Heleno et al., 2012). It highlights the robustness of an ecological network (Romanuk et al., 2017).

In a food web, the influence of structure on stability has been widely proved, yet the key factors for determining stability remain nonobvious (Rooney and McCann, 2012). The species richness is the basis of the complex structure in food webs (Hall and Raffaelli, 1991), including the topology and interactions patterns. This complicity shows that the link density grows with the increasing of taxon (Martinez et al., 1999; Gravel et al., 2011). Each species may link to other species including itself, but in food web chain if a species A feeds on species B, this link is not equal if B could feed on A.

Terrestrial and aquatic food webs are characterized by the same parameters as connectance, robustness and linkage. Nonetheless, primary structures of ecological unit and their regular features constitute basic differences in ecosystems (Lindeman, 1942; Strong, 1992; Chase, 2000; Mougi and Kondoh, 2016). The literature shows dissimilarities amongst food webs from terrestrial and aquatic habitats, specifically in the species' growth both in rate and size, and autotrophs' dietary features (Shurin et al., 2006). Except cited parameters, further differences between aquatic and terrestrial food webs according to complexity, connectance and linkage (even robustness, Dunne et al., 2002a) still need to be clarified, and in addition, the common and dissimilarities in food webs topology between terrestrial and aquatic ecosystems have not yet been wholly clarified (Rossi et al., 2015). Only a few studies have explored the role of habitat on a small subset of trophic interacting species (Melian et al., 2005). Indeed, many researchers approve dissimilarities in terrestrial and aquatic ecological networks, yet at the trophic pathways level little studies have quantified these disparities (Shurin et al., 2006; van Altena et al., 2016). Hence two issues emerge: (1) Do food webs from aquatic and terrestrial habitats have the same proportions of link density? (2) Amongst these environmentally different food webs, does one might be more connected than another? This study attempts to compare three attribute patterns (connectance, link density and average length of chain) between aquatic and terrestrial food webs and bring out major features presence magnitude influencing food webs in these two habitats type.

\section{Methods}

\section{Study presentation}

We conducted literature review found from diverse research browsers to collect as many documents as possible related to all attributes used in this study and those related 
to any characteristic depicting difference in habitats influencing a food web. We realized that the functioning of food webs and their structure are mostly characterized and influenced by their own different structural attributes. These attributes are constitutive elements of the complexity (diversity, connectance, robustness, nestedness, pathway proliferation and link distribution) and portray the state of the community networks (Canning and Death, 2017). Though, all of them don't necessarily influence stability of the food web (May, 1973; Riede et al., 2010). In our study methodology, we preferred first to understand these attributes; (a) connectance which is the fraction of undertaken interactions from the pool of all probable interactions between members of a network (May, 1973; Calizza et al., 2015). (b) Trophic link which is a reported feeding relationship between two species in a food web (Martinez, 1992). Ecologists use different criteria to decide how much foods validate the presence or the absence of a link (Cohen and Briand, 1984). (c) Average length chain which represents the average link number of chain within a food web from the basis till the top predators, without considering loops (Calizza et al., 2015). (d) Robustness which is the opposite of fragility, and it relates to the preservation of network integrity and so has effects on stability (Gilbert, 2009). (e) Nestedness: a network always has two kinds of species: generalists and specialists (Henle et al., 2004). Thus the interactions in a network are nested when the species interacting with specialists constitute a subgroup of the species interacting with generalists (Tylianakis et al., 2010).

\section{Analysis}

Many food webs of different habitats were considered in this study. Selection of the food webs was based on criteria such as common elements and belonging to the same collection (Table 1). We calculated the connectance (Gardner and Ashby, 1970; Williams and Martinez, 2000; van Altena et al., 2016; Romanuk et al., 2017) by

$$
C=L / S^{2}
$$

where $C$ represents the connectance; $L$ is the number of trophic links and $S$ is the species richness.

The link density was computed (Hall and Raffaelli, 1993; Bersier et al., 1999; Tylianakis et al., 2010; Gravel et al., 2011; Calizza et al., 2015) by

$$
L D=L / S
$$

where $D L$ indicates link density $L$ and $S$ are same as equation (1).

Analysis of variance (ANOVA) was used to test if there was a significant difference within connectance of different habitats' food webs and link density values. Normality of the data was checked using the Shapiro test and the homoscedasticity using the Bartlett test (Koller et al., 2007; James et al., 2013). We demonstrated the involvement of connectance with two other attributes (link density and the average length of chain) by the correlation test (Pearson test), and we computed the regression boxplots to demonstrate this correlation power (Koller et al., 2007). Due to the outputs of the correlation test, multiple regressions were computed (in $\mathrm{R}$ software) by postulating the connectance as the dependent variable with link density and average length of chain as predictors, to predict how predictors influence the dependent variable, and how they are really associated (Faraway, 2016). We made a set of principal functioning patterns in 
aquatic and terrestrial ecosystems which govern the feeding interactions from previous studies and discussed about their properties and influences on food web within studied habitats. The interpretation of estimates from computed attributes and dissimilarities pulled from literature constituted the basis of inferences herein this study.

Table 1. Analyzed food weds (Source: Cohen et al., 1990)

a. Terrestrial food webs

\begin{tabular}{c|c|c|c|c|c|c}
\hline Food webs name in the collection & $\boldsymbol{S}$ & $\boldsymbol{L}$ & $\boldsymbol{C}$ & $\boldsymbol{L D}$ & $\boldsymbol{A L C}$ & No \\
\hline Prairie, Manitoba & 15 & 27 & 0.12 & 1.8 & 2.4 & 23 \\
Willow forest, Manitoba & 12 & 18 & 0.13 & 1.5 & 2.7 & 24 \\
Aspen communities, Manitoba & 24 & 37 & 0.06 & 1.54 & 2.93 & 25 \\
Aspen forest, Manitoba & 32 & 56 & 0.05 & 1.75 & 2.93 & 26 \\
Wytham Wood, England & 22 & 39 & 0.08 & 1.77 & 2.89 & 27 \\
Salt meadow, New Zealand & 32 & 35 & 0.03 & 1.09 & 1.96 & 28 \\
Rain forest, Malaysia & 11 & 15 & 0.12 & 1.36 & 1.88 & 40 \\
Sand beach, California & 14 & 23 & 0.12 & 1.64 & 2.44 & 50 \\
Trelease Woods, lllinois & 29 & 61 & 0.07 & 2.1 & 2.37 & 59 \\
Montane forest, Arizona & 33 & 69 & 0.06 & 2.09 & 2.36 & 60 \\
Barren regions, Spitsbergen & 8 & 10 & 0.16 & 1.25 & 2 & 61 \\
Reindeer pasture, Spitsbergen & 11 & 12 & 0.10 & 1.09 & 3 & 62 \\
Sand beach, South Africa & 21 & 36 & 0.08 & 1.71 & 2.38 & 74 \\
Old field New Jersey & 22 & 39 & 0.08 & 1.77 & 1.84 & 90 \\
Shigayama coniferous forest, Japan & 10 & 13 & 0.13 & 1.3 & 3 & 91 \\
High Himalayas community, Tibet & 18 & 18 & 0.06 & 1 & 2 & 92 \\
Alpine tundra, Montana & 26 & 70 & 0.10 & 2.69 & 2.12 & 93 \\
Tundra, Prudhoe, Alaska & 10 & 12 & 0.12 & 1.2 & 2.5 & 95 \\
Tundra, Yamal Peninsula, Siberia & 9 & 16 & 0.20 & 1.78 & 1.92 & 96 \\
Tundra, South Yamal, Siberia & 11 & 17 & 0.14 & 1.55 & 2 & 97 \\
Sand dunes, Namib Desert, Namibia & 17 & 39 & 0.13 & 2.29 & 3.54 & 98 \\
Sonora Desert, Arizona & 48 & 138 & 0.06 & 2.88 & 2.51 & 99 \\
Rajasthan Desert, India & 22 & 59 & 0.12 & 2.68 & 3.34 & 100 \\
\hline
\end{tabular}

b. Lacustrine food webs

\begin{tabular}{c|c|c|c|c|c|c}
\hline Food webs names in the collection & $\boldsymbol{S}$ & $\boldsymbol{L}$ & $\boldsymbol{C}$ & $\boldsymbol{L D}$ & $\boldsymbol{A L C}$ & No \\
\hline Lough Ine Rapids, Ireland & 9 & 13 & 0.16 & 1.44 & 2.86 & 9 \\
Moosehead Lake, Maine & 17 & 32 & 0.11 & 1.88 & 3 & 19 \\
Lake Nyasa, rocky shore, Malawi & 31 & 95 & 0.10 & 3.06 & 2.13 & 38 \\
Lake Nyasa, sandy shore, Malawi & 33 & 70 & 0.06 & 2.12 & 1.8 & 39 \\
Lake Texoma, Texas & 19 & 68 & 0.19 & 3.58 & 4.43 & 46 \\
Lake Rybinsk, Russia, USSR & 16 & 32 & 0.13 & 2 & 5.15 & 71 \\
Heney Lake, pelagic zone, Quebec & 17 & 32 & 0.11 & 1.88 & 3.95 & 72 \\
Hafner Lake, Austria & 10 & 15 & 0.15 & 1.5 & 2.38 & 73 \\
Vorderer Finstertaler Lake, Austria & 9 & 14 & 0.17 & 1.56 & 2.75 & 75 \\
Neusiedler Lake, Austria & 14 & 17 & 0.09 & 1.21 & 2.67 & 76 \\
Lake Abaya, Ethiopia & 13 & 24 & 0.14 & 1.85 & 3.63 & 77 \\
Lake George, Uganda & 16 & 27 & 0.11 & 1.69 & 3.15 & 78 \\
Lake Piijirvi, offshore, Finland & 21 & 29 & 0.07 & 1.38 & 3.41 & 79 \\
Lake Piijirvi, littoral zone, Finland & 27 & 70 & 0.10 & 2.59 & 3.35 & 80 \\
Lake PyhajiU-vi,littoral zone, Finland & 25 & 67 & 0.11 & 2.68 & 2.45 & 83 \\
\hline
\end{tabular}


c. Rivers (and creeks) food webs

\begin{tabular}{c|c|c|c|c|c|c}
\hline Food Webs name in the collection & $\boldsymbol{S}$ & $\boldsymbol{L}$ & $\boldsymbol{C}$ & $\boldsymbol{L D}$ & $\boldsymbol{A L C}$ & No \\
\hline Crocodile Creek, Malawi & 29 & 48 & 0.06 & 1.66 & 1.93 & 33 \\
River Clydach, Wales & 12 & 27 & 0.19 & 2.25 & 2.56 & 34 \\
Morgan's Creek, Kentucky & 13 & 36 & 0.21 & 2.77 & 2.72 & 35 \\
River Rheidol, Wales & 18 & 75 & 0.23 & 4.17 & 3.16 & 63 \\
Linesville Creek, Pennsylvania & 19 & 28 & 0.08 & 1.47 & 1.67 & 64 \\
Yoshino River rapids, Japan & 13 & 25 & 0.15 & 1.92 & 1.85 & 65 \\
River Thames, England & 10 & 18 & 0.18 & 1.8 & 2.93 & 66 \\
Mudflats, Mississippi River, Iowa & 21 & 62 & 0.14 & 2.95 & 3.94 & 67 \\
Crystal River Estuary, Florida & 14 & 28 & 0.14 & 2 & 2.49 & 70 \\
Lestijoki River Rapids, Finland & 16 & 42 & 0.16 & 2.63 & 1.95 & 88 \\
River Cam, England & 18 & 32 & 0.10 & 1.78 & 2.89 & 89 \\
\hline
\end{tabular}

$S$ : number of species; $L$ : number of links; $C$ : connectance; $L D$ : link density; $A L C$ : average length of chain; No: number of food web in Cohen's collection

\section{Results}

\section{Data set and fitness of statistical tests}

The analysed food webs were from Cohen et al. (1990) collection. Among the 55 continental food webs of the collection, 49 were studied (Table 1). They are apportioned in 23 terrestrials, 15 lacustrine and 11 rivers and creeks which are referred to as simply rivers' food web in this study. Within the sample, 18 food webs $(36.73 \%)$ of the considered collection were from America, 16 (32.65\% of the collection) from Europe, Africa and Asia had 7 food webs each (constituted 14.28\% of our data set for each continent) and only one food web from Oceania which represented $2.04 \%$. We computed their studied attributes: connectance, link density and the average length chain. All tests (except one) to verify the requirements of the analysis proved that our data were fitted for ANOVA. Shapiro test $p=0.957$ and Bartlett test $p=0.400$ for connectance, Shapiro test $p=0.001$ and Bartlett test $p=0.296$ for link density. The Shapiro test for link density had $p<0.050$, but it didn't influence the analysis as other requirements were successfully fulfilled (e.g. James et al., 2013).

\section{Findings for studied attributes of food webs in three habitats}

Findings revealed differences between connectance within three habitats $(p=0.012)$, with averages of $0.101 ; 0.118$ and 0.149 for terrestrial, lacustrine and rivers, respectively. Comparing link density values, the $p=0.048(\sim 0.05)$, revealed an absence of significant difference and averages were 1.732; 2.028 and 2.308 for terrestrial, lacustrine and rivers respectively. Their boxplots (Figure 1) represent these averages and they revealed an increasing pace from terrestrial to rivers' habitat.

The correlation tests of connectance with link density and connectance with average length of chain revealed an inversely correlated relation in terrestrial habitats (Table 2); on the other hand, in two other habitats (lacustrine and rivers) they were positively correlated but not significantly. 


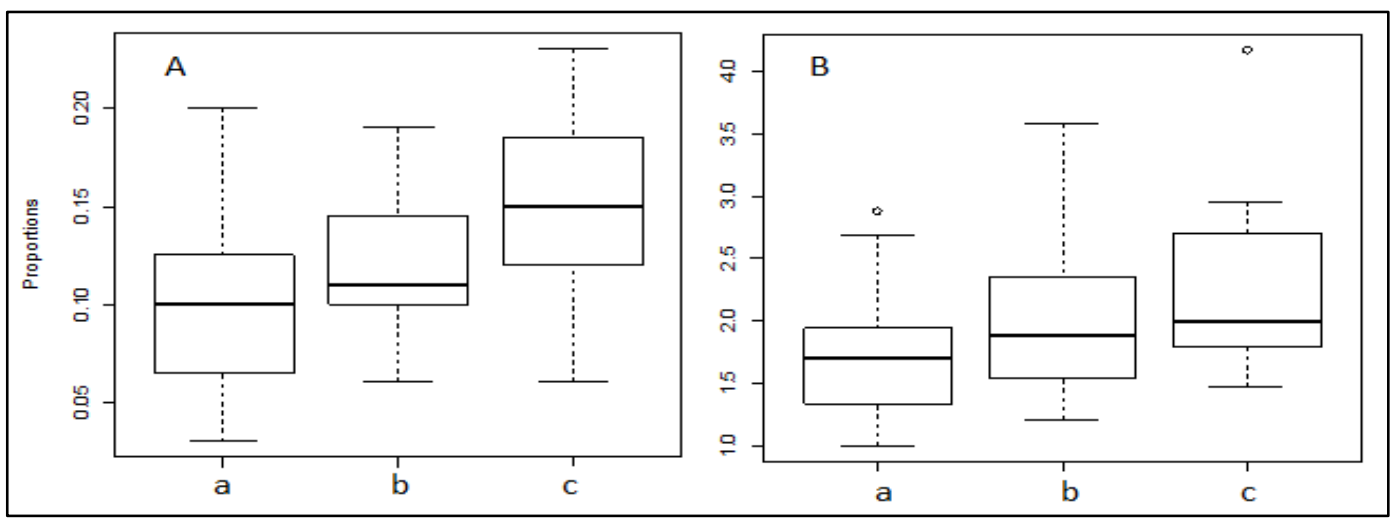

Figure 1. Different averages rate of connectance $(A)$ and link density $(B)$ in food webs, a: terrestrial; $b$ : lacustrine and $c$ : rivers

Table 2. Correlation estimates of attributes in three habitats

\begin{tabular}{c|cc|cc|cc}
\hline \multirow{2}{*}{ Estimated } & \multicolumn{2}{|c|}{ Terrestrial } & \multicolumn{2}{c|}{ Lacustrine } & \multicolumn{2}{c}{ Rivers } \\
\cline { 2 - 7 } Parameters & $\boldsymbol{C}$ - $\boldsymbol{D} \boldsymbol{D}$ & $\boldsymbol{C}$ - $\boldsymbol{A} \boldsymbol{L} \boldsymbol{C}$ & $\boldsymbol{C}$ - $\boldsymbol{D}$ & $\boldsymbol{C}$ - $\boldsymbol{A} \boldsymbol{C}$ & $\boldsymbol{C}$ - $\boldsymbol{D}$ & $\boldsymbol{C}$ - $\boldsymbol{A} \boldsymbol{L} \boldsymbol{C}$ \\
\hline$r$ & -0.054 & -0.041 & 0.178 & 0.362 & 0.727 & 0.420 \\
$r$-squared & 0.003 & 0.002 & 0.031 & 0.131 & 0.529 & 0.177 \\
$p$-value & 0.803 & 0.849 & 0.520 & 0.184 & 0.011 & 0.1973 \\
\hline
\end{tabular}

$C$ : connectance, $L D$ : link density and $A L C$ : average length of chain

A more thorough visual examination was needed, so we used scatter diagrams and variations as demonstrated through the boxplots histogram (Figure 2).

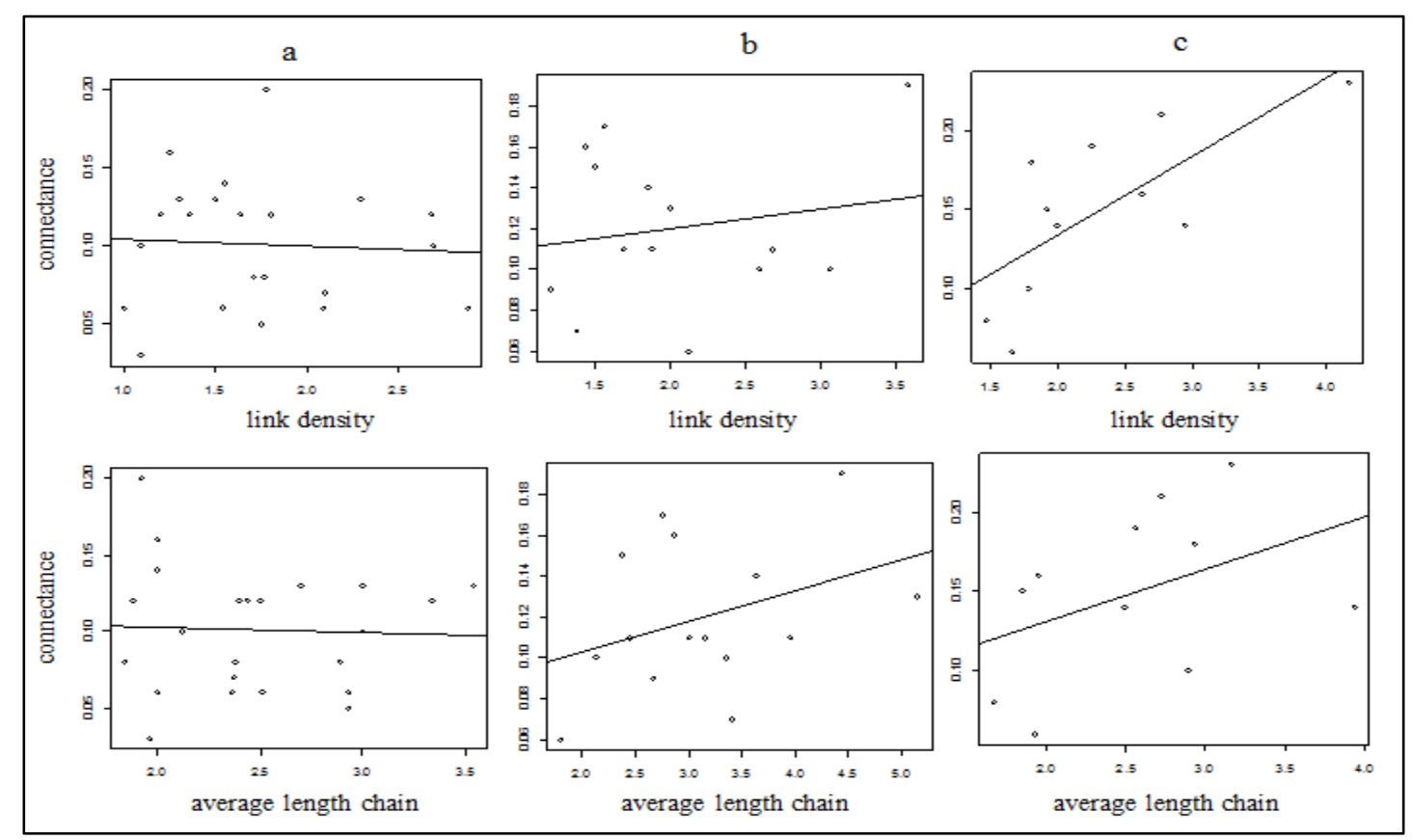

Figure 2. Correlation diagrams (column a: terrestrial, column b: lacustrine and column c: rivers) 
We computed a multiple regression test for these three attributes (Table 3). The model depicted lesser influences of both link density and average length of chain on the connectance (dependent variable) in all habitats, except link density in rivers which had $p<0.05$. Within lacustrine food webs, correlations of connectance with link density; and connectance with average length of chain were positive but weak, with $3.19 \%$ and $13.13 \%$ of explained variations. In rivers, an average and positive correlation (Table 2) for connectance with link density was brought out (with $52.95 \%$ as explained variation). According to connectance with average length of chain, a positive but non-significant correlation was found (17.72\% explained variation).

Table 3. Multi-regression models output for three different habitats' attributes; with connectance as the dependent variable and link density and average length of chain as predictors

\begin{tabular}{c|ccc|ccc|ccc}
\hline \multirow{2}{*}{$\begin{array}{c}\text { Estimated } \\
\text { parameters }\end{array}$} & \multicolumn{3}{|c|}{ Terrestrial } & \multicolumn{3}{c|}{ Lacustrine } & \multicolumn{3}{c}{ River } \\
\cline { 2 - 10 } & Inter & $\boldsymbol{C}-\boldsymbol{D L}$ & $\boldsymbol{A L C}$ & Inter & $\boldsymbol{L D}$ & $\boldsymbol{A L C}$ & Inter & $\boldsymbol{L D}$ & $\boldsymbol{A L C}$ \\
\hline Estim & 0.113 & -0.003 & -0.002 & 0.061 & 0.006 & 0.014 & 0.032 & 0.048 & 0.001 \\
$S E$ & 0.049 & 0.017 & 0.019 & 0.043 & 0.014 & 0.011 & 0.051 & 0.019 & 0.022 \\
$t$ & 2.265 & -0.203 & -0.012 & 1.427 & 0.479 & 1.271 & 0.628 & 2.449 & 0.067 \\
$p$-value & 0.034 & 0.841 & 0.900 & 0.179 & 0.641 & 0.228 & 0.547 & 0.040 & 0.949 \\
\hline
\end{tabular}

Inter: intercept, Estim: estimates, $S E$ : standard error, $t$ : test-values, $C$ : connectance, $L D$ : link density and $A L C$ : average length of chain

\section{Differential view of habitats}

After computing attributes of studied food webs; we retrieved important dissimilarities which refer directly or indirectly to at least one of the major attributes within a feeding network, in either terrestrial or aquatic habitat (Table 4). There are many internal characteristics in both of these two habitats, but we chose the most important cited in previous food webs studies, and these characteristics seemed to be largely documented. Although the habitat type cannot portray the entire food web characteristics, the dynamics of ecosystem features contribute to the functioning of food web patterns within a habitat and can exert a certain influence.

Table 4. Other peculiarities in two different habitats' food webs

\begin{tabular}{c|c|c|c}
\hline Attributes & A-food webs & T-food webs & Sources \\
\hline Productivity & low & high & (Chase, 2000) \\
Complexity & low & high & (Chase, 2000) \\
Omnivory & low & high & (Thompson et al., 2012a) \\
Diversity & low & high & (Strong, 1992; Caizza et al., 2015) \\
Trophic levels & more than(4) & less than(3) & (Hairston and Hairston, 1993) \\
Trophic cascades & common & rare & (Chase, 2000) \\
Interactions & strong & weak & (Polis, 1999) \\
Size-structured & strong & less & (Shurin et al., 2006) \\
Growth rates & fast & slow & (Shurin et al., 2006) \\
Elton's rule (biomass & not applied & applied & (Elton, 1927) \\
pyramid) & unicellular & multicellular & (Linderman, 1942) \\
Primary producers & more & less & (Linderman, 1942) \\
Nutrients & great & little & (Shurin et al., 2006) \\
Living plants & & & \\
consumption & &
\end{tabular}

A: Aquatic and T: terrestrial 


\section{Discussion}

\section{Data set and methodological assessment}

The choice of our food web samples from the Cohen et al. (1990) collection was justified as this collection remains one of the most detailed and well explained. Only continental food webs constituted our sample. Wetlands and estuarine food webs were excluded due to interpretation issues of the location definition, as stated by Cohen (1994), and the dichotomy between oceans and continents excludes coastal zones, which some argue give them an intermediate status. Our methodology was adapted to use tests in the study, and allowed us to calculate estimates of studied attributes (connectance, link density and length of the chain) chosen because of their importance in measuring connectivity of a food web as stressed by Tylianakis et al. (2010), and making comparisons between food webs belonging to two habitats type: terrestrial and aquatic. Despite that the methodological approaches were mostly based on empirical facts in the food webs estate, we assumed this analysis was not ultimately perfect due to the complexity of food web domain, referring to Power (1992) who admitted the difficulties in applying food web theories to real ecosystems. Nevertheless, despite in real networks, food webs are greatly complex than the literature could let us think (Polis, 1988; Bolchoun et al., 2017), this study brought out details about differences in food webs in different habitats type. We used the geometric average length of chain.

\section{Features of studied attributes in three habitats' food webs}

The connectance values were different among three habitats $(p=0.012)$ with aquatic food webs being more connected. The features diversity within ecosystems should probably justify this dissimilarity. Ecological systems vary in their basic configurations that govern their features and complexity (Lindeman, 1942; Strong, 1992; Chase, 2000; Riede et al., 2010), and they differ within terrestrial and aquatic habitat. Food webs' parameters such as quality and quantity of interactions, the size of the structure (Dunne et al., 2002b), and growth rate of organisms have a central role in depicting this difference as they are stronger in aquatic than terrestrial habitats (Polis, 1999; Shurin et al., 2006) that would explain the dissimilarity in food web connections as found in our results, despite analyses of Riede et al. (2010) and Rossi et al. (2015) demonstrated that ecosystem-specific differences were of minor importance in food webs features. However, comparing the observed $p$-value to the 0.01 threshold there were no significant differences. Accordingly, these estimates did not have a high variation between habitats as intragroup variances were the same $(p=0.4005$, Bartlett test $)$ and averages were $0.101 ; 0.118$ and 0.149 for terrestrial, lacustrine and river food webs, respectively. Our findings corroborated those of Riede et al. (2010) when they studied the scaling of food web properties from five different food web habitats (estuary, lake, marine, river and terrestrial). These slight differences found in averages show the difference of connectivity features between terrestrial and aquatic food webs, yet the average values demonstrate clearly the non-significant aspect of that difference, as it was demonstrated by results found.

The average values for connectance and link density in aquatic habitats were higher than terrestrial. Calizza et al. (2015) observed that link density and connectance always describe the complex structure of the food webs regarding their size dissimilarities, while the average length chain portrays the average number of trophic transfers from detritus resources to top predators. Thus these two metrics are linked by such feature. 
Indeed, trophic links are one of attributes which have never lacked in a food web (Neutel et al., 2002; Pinnegar et al., 2005) since food web studies shown that a great number of species (more than 95\%) are within three links of one another (Gravel et al., 2011). The upper limit of links is the square of the species number; each species cannot be linked to more species than exist in a web. The lowest link number is species' number minus one, as each species must be connected to a food web with at least one link (Martinez, 1992; Gravel et al., 2011). Nonetheless, some habitats have a high number of links, connectance and average length of chain as stated by Dunne et al. (2004) which agree with this study as aquatic food webs were revealed to be more connected.

Terrestrial habitat had an inverse correlation between connectance and two other attributes (link density and average length of chain), with $R$-squared values of 0.003 and 0.002 estimates, respectively, and explained variations of only $0.30 \%$ and $0.20 \%$, respectively for link density and average length of chain. When the species richness approaches infinity, it generates the smallest connectance (Gilbert, 2009); and endorses the inverse proportionality with link density. As connectance and link density are inversely connected in terrestrial food webs, Dunne (2012) stated that the highest number of links in a food web is consequently, the square of the species number present in that food web. A positive correlation is always found between species and the number of links within a trophic chain, contrary with connectance. As links and species are positively correlated in term of number, interactions will depend on the correlation because they are underlying and defined by link number. These results corroborate the theory stipulated that food webs should not accumulate the largest numbers of species (McCann et al., 1998) therefore connectance and robustness wouldn't be affected. However, connectance, in its simple interpretation cannot be considered as an indicator of stability, as its value is typically attributed (Helano et al., 2012). In this optic, it should be careful to interpret connectance values in order to avoid a generalization of a trend in specific case as new approaches introduced the notion of weighted and unweighted connectance (Van Altena et al., 2016). Yet, in general the studied connectance remains unweighted as the weighted connectance has never been used in the complexity-stability context and it is focused on flux transmission in a food web.

While interpreting correlation, researchers always conclude that "there is no strong relationship between the two variables". This explanation is simply a reflection of reality. It is then necessary to leave the simple correlations and make multipleregressions, so we computed a multiple regression test (Table 3). This test even elucidates the lack of dependence amongst connectance with link density and average length of chain in all habitats (except link density in rivers), but the prediction of influence in this association remains blurry, particularly in terrestrial food webs. Specific internal features of an ecosystem explain that connectance in terrestrial food webs withstands whatever the effects of the length of chain. For example, productivity, complexity (Chase, 2000), diversity (Strong, 1992), and omnivory (McCann and Hastings, 1997) are all strong in terrestrial habitats, and they are key attributes in depicting stability. Yet recently, it has been stated that a very strong omnivory effect can destabilize a food web (Gellner and McCann, 2012).

Compared to terrestrial habitats, link density and average length of chain in lacustrine food webs are less responsible for connectance variations (3.19\% and $13.13 \%$, respectively). The explained variation values were low, thus other probable factors such as fluxes and interaction strengths should empirically explain this disparity as the more 
consistently flux rates are distributed over links in a food web, the more stable the webs are (van Altena et al., 2016).

Rivers depicted positive correlations with average values for explained variations (52.95\% for link density and $17.72 \%$ for average length of chain). That demonstrated the difference between terrestrial and aquatic habitats. Evidence shows that although food webs share a fundamental organization that depends on the number of species and network linkages (Dunne et al., 2004), it is useful to recognize whether there are fine structural differences between different habitats type. Cohen (1994) found contrasts between marine food webs as they had greater link density and length of chain than their equivalents in terrestrial and freshwater ecosystems. Obviously, the properties of food webs are actually dissimilar in each specific habitat. In this perspective, the scaledependence of most food web properties has been well recognized because they change as species richness and complexity change (Martinez, 1993; Riede et al., 2010). Nonetheless, it was proved that some food web properties remain scale-invariant (Sugihara et al., 1989; Cohen et al., 1990; Hall and Raffaelli, 1993) with one exception the links/species ratio (Strong, 1988; Martinez, 1994). This could be a plausible explanation for these findings according to the correlation between connectance and link density, especially in aquatic food webs, as terrestrial food webs tended to conform to the scale invariant properties patterns.

\section{Differential view of food webs in habitats}

Trophic cascades are more observed in aquatic food webs, even though facts have never been proved (Chase, 2000). Yet, Hairston et al. (1960) assumed that reduction of the abundance of herbivores in terrestrial food webs when apex carnivores are numerous, allows plants to flourish, and leads to a trophic cascade. Therefore, the most obvious understanding of this fact is that species on which the robustness of a food web is most dependent should be the greatest priority for conservation (McDonald-Madden et al., 2016). In aquatic habitat a trophic cascade may be natural, but in a terrestrial habitat it should depend on apex carnivores. We stress that the Elton's rule (biomass pyramid) is not often applied in aquatic food webs contrary to terrestrial (Elton, 1927). It was well documented that in ascending movement within a food web chain, the biomass decreases at each level. A perfect illustration of the energy transfer through a chain in a food web is a pyramid of biomass. Nonetheless, seasonal disparities in the turnover degree of species at a specific level might result in superior or inferior values for the quantity of biomass sampled at a precise period than the normal quantity across the year. Thus, the turnover is easily triggered in aquatic habitats because of the high abundance of nutrients (Lindeman, 1942) and leads to failure to apply Elton's rule. However, eutrophication is mainly responsible for high nutrient abundance in aquatic habitats (Khan et al., 2014), therefore the pyramid of energy is the best representation of the transfer of energy in a chain of a food web which is applicable in both aquatic and terrestrial habitats.

Terrestrial ecosystems present a high diversity and complexity level (Strong, 1992; Hairston and Hairston, 1993) that induces high productivity (Chase, 2000). Indeed, in terrestrial systems, plant defence is widespread (Polis, 1999) but aquatic systems promote small and floating species, rather than those that are generally well selfdefended (Polis and Strong, 1996; Persson, 1999). Accordingly, plant defence also increases complexity in terrestrial habitats. However, this complexity (and diversity) might be influenced by seasonality (Pimm, 1982; Thompson et al., 2012b) and even 
with high complexity, terrestrial food webs have fewer interactions than aquatic ones (Polis, 1999). We assumed that connectance should be positively correlated with interactions because this study found a high connectance in aquatic than in terrestrial habitat. Thus food webs of freshwater are more connected than terrestrial, which is in agreement with Dunne et al. (2004) for marine areas. Robustness increases with connectance (Dunne et al., 2002a, 2004; Canning and Death, 2017) and regarding species loss (Gilbert, 2009) food webs of freshwater habitats are more robust than their terrestrial counterparts. Marine food webs depicted the same feature (Dunne et al., 2004), as this system allows its food webs to remain robust to a selected loss of wellconnected species, due to their high connectance (Albert and Barabasi, 2000; Zhao et al., 2016; Canning and Death, 2017). This fact pertains to the theory of "a loss of less connected species in a chain creates a positive change in the connectance" (Gilbert, 2009), and we infer that habitats in continental waters have more robust food webs than terrestrial as it is the case for marine habitats.

The Trophic levels are more abundant in aquatic food webs than in terrestrial (Hairston and Hairston, 1993). Some ecologists stipulate that there is no evidence for such trend, principally because of issues to estimate the species diversity or richness and links of small sized organisms in aquatic (Schmid-Araya et al., 2002), terrestrial, and soil ecosystems (Mikola and Setälä, 1998). Many trophic levels can present omnivory, which has a positive role in food web stability, contrary to what early studies stipulated (McCann and Hastings, 1997). This attribute is low in aquatic than in terrestrial food webs (Thompson et al., 2012a), and should explain why omnivory cannot influence robustness (Dunnne et al., 2002) as both of them are not highly present in a food web. However, Gellner and McCann (2012) stipulated that strong omnivory can destabilize a food web. Definitively, although food web dissimilarities exist between ecosystems, landscapes or habitats, the "who feed on whom patterns" are more similar within food web pertaining to those habitat types (e.g. Riede et al., 2010; Rossi et al., 2015).

\section{Conclusion}

Despite numerous studies by ecologists using multi methodological ways, food web research domain remains complex. Researchers always approve issues in applying food web theories to the real world in ecosystems. Different inferences have been established, but most of them are specific or isolate case, therefore they do not reveal the actual situation in many landscapes. After a documentary analysis, we realised that aquatic food webs are more studied than terrestrial; they are more connected and robust as robustness increases with connectance. Nevertheless, aquatic food webs are more sensitive than terrestrial ones to the loss of connected species in a chain. Many links reduce robustness so it is not necessarily true that more links bring stability, which needs to be empirically proved. Complexity is higher in terrestrial food webs than in aquatic, because many links determine the complexity, and they are opposite to robustness which is high in aquatic systems. Unlike in aquatic systems, connectance and link density are inversely correlated in terrestrial ecosystems. Although food webs share a fundamental organization, there are fine structural differences between habitats. Yet this study should not be the ultimate confirmation of facts underlying its findings since more studies are required to demonstrate new patterns which could support such inferences. Consequently, we suggest researchers to continue going beyond this study in the same thematic. 
Acknowledgements. This research was funded by North China Leopard Monitoring Demonstration of NFGA, National Natural Science Foundation of China (NSFC 31872241). We thank our colleagues in the Feline Research Center of National Forestry and Grassland Administration of the Northeast Forestry University for their valuable advices and suggestions during the preparation of this study; we particularly thank Meadhbh Molloy and Chula Mwagona Pateson for language corrections and valuable orientations.

\section{REFERENCES}

[1] Albert, R., Barabasi, A. L. (2000): Topology of evolving networks: local events and universality. - Physical Review Letters 85: 5234-5237.

[2] Bascompte, J., Jordano, P. (2007): Plant-animal mutualistic networks: the architecture of biodiversity. - Annual Review of Ecology, Evolution, and Systematics 38: 567-593.

[3] Bersier, L. F., Dixon, P., Sugihara, G. (1999): Scale-invariant or scale-dependent Behavior of the link density property in food webs: a matter of sampling effort? American Naturalist 153: 676-682.

[4] Bolchoun, L., Drossel, B., Allhoff, K. T. (2017): Spatial topologies affect local food web structure and diversity in evolutionary metacommunities. - Scientific Reports 7: 1-11.

[5] Boogert, J. N., Paterson, M. D., Laland, K. N. (2006): The Implications of Niche Construction and Ecosystem Engineering for Conservation Biology. - BioScience 56: 570-578.

[6] Calizza, E., Costantini, M. L., Rossi, L. (2015): Effect of multiple disturbances on food web vulnerability to biodiversity loss in detritus-based systems. - Ecosphere 6: 1-20.

[7] Canning, A. D., Death, R. G. (2017): Trophic cascade direction and flow determine network flow stability. - Ecological Modelling 355: 18-23.

[8] Chase, J. M. (2000): Are there real differences among aquatic and terrestrial food webs? Trends in Ecology \& Evolution 15: 408-412.

[9] Cohen, J. E., Briand, F. (1984): Trophic links of community food webs. - Proceedings of the National Academy of Sciences 81: 4105-4109.

[10] Cohen, J. E., Briand, F., Newman, C. M. (1990): Community food webs: data and theory. - Springer-Verlag, New York.

[11] Cohen, J. E. (1994): Marine and continental food webs: three paradoxes? - Philosophical Transactions of the Royal Society B Biological 343: 57-69.

[12] Dunne, J. A., Williams, R. J., Martinez, N. D. (2002a): Network structure and biodiversity loss in food webs: robustness increases with connectance. - Ecological Letters 5: 558-567.

[13] Dunne, J. A., Williams, R. J., Martinez, N. D. (2002b): Food-web structure and network theory: the role of connectance and size. - Proceedings of the National Academy of Sciences 99: 12917-12922.

[14] Dunne, J. A., Williams, R. J., Martinez, N. D. (2004): Network Structure and Robustness of Marine Food Webs. - Marine Ecology Progress Series 273: 291-302.

[15] Dunne, J. A. (2012): Food webs: Computational complexity theory, techniques and applications. - Springer-Verlag, New York.

[16] Elton, C. (1927): Animal Ecology. - MacMillan, New York.

[17] Faraway, J. J. (2016): Linear models with R. - Chapman and Hall/CRC, New York.

[18] Gardner, M. R., Ashby, W. R. (1970): Connectance of large dynamical (cybernetic) systems: critical values for stability. - Nature 228: 784-784.

[19] Gellner, G., McCann, K. (2012): Reconciling the Omnivory-Stability Debate. - American Naturalist 179: 22-37.

[20] Gilbert, A. J. (2009): Connectance indicates the robustness of food webs when subjected to species loss. - Ecological Indicators 9: 72-80. 
[21] Gravel, D., Canard, E., Guichard, F., Mouquet, N. (2011): Persistence Increases with Diversity and Connectance in Trophic Metacommunities. - PLoS ONE 6: e19374. doi:10.1371/journal.pone.0019374.

[22] Hagen, M., Kissling, W. D., Rasmussen, C., Carstensen, D. W., Dupont, Y. L., KaiserBunbury, C. N., O'Gorman, E. J., Olesen, J. M., De Aguiar, M. A. M., Brown, L. E., Alves-Dos-Santos, I., Guimarães, P. R., Maia, K. P., Marquitti, F. M. D., Vidal, M. M., Edwards, F. K., Genini, J., Jenkins, G. B., Trøjelsgaard, K., Woodward, G., Jordano, P., Ledger, M. E., Mclaughlin, T., Morellato, L. P. C., Tylianakis, J. M. (2012): Biodiversity, Species Interactions and Ecological Networks in a Fragmented World. - Advances in Ecological Research 46: 89-120.

[23] Hairston, N. G., Smith, F. E., Slobodkin, L. B. (1960): Community structure, population control, and competition. - American Naturalist 94: 421-425.

[24] Hairston Jr, N. G., Hairston Sr, N. G. (1993): Cause-effect relationships in energy flow, trophic structure, and interspecific interactions. - American Naturalist 142: 379-411.

[25] Hall, S. J., Raffaelli, D. G. (1991): Food-web patterns: lessons from a species-rich web. Journal of Animal Ecology 60: 823-842.

[26] Hall, S. J., Raffaelli, D. G. (1993): Food webs: theory and reality. - Advances in Ecological Research 24: 187-239.

[27] Heleno, R., Devoto, M., Pocock, M. (2012): Connectance of species interaction networks and conservation value: Is it any good to be well connected? - Ecological Indicators 14: 7-10.

[28] Henle, K., Davies, K. F., Kleyer, M., Margules, C., Settele, J. (2004): Predictors of species sensitivity to fragmentation. - Biodiversity \& Conservation 13: 207-251.

[29] James, G., Witten, D., Hastie, T., Tibshirani, R. (2013): An introduction to statistical learning. - Springer, New York.

[30] Jordano, P. (2016): Chasing ecological interactions. - PLOS Biology 14: e1002559.

[31] Khan, F. A., Naushin, F., Rehman, F., Masoodi, A., Irfan, M., Hashmi, F. (2014): Eutrophication: global scenario and local threat to dynamics of aquatic ecosystems. - In: Eutrophication: causes, consequences and control. Springer, Dordrecht.

[32] Koch, H., Frickel, J., Valiadi, M., Becks, L. (2014): Why rapid, adaptive evolution matters for community dynamics. - Frontiers in Ecology and Evolution 2: 1-17.

[33] Koller, D., Friedman, N., Džeroski, S., Sutton, C., McCallum, A., Pfeffer, A., Abbeel, P., Wong, M. F., Heckerman, D., Meek, C., Neville, J. (2007): Introduction to statistical relational learning. - MIT Press, Massachusetts.

[34] Lindeman, R. (1942): The trophic-dynamic aspect of ecology. - Ecology 23: 399-418.

[35] Martinez, N. D. (1992): Constant connectance in community food webs. - American Naturalist 139: 1208-1218.

[36] Martinez, N. D. (1993): Effects of Resolution on Food Web Structure. - Oikos 66: $403-$ 412.

[37] Martinez, N. D. (1994): Scale-Dependent Constraints on Food-Web Structure. American Naturalist 144: 935-953.

[38] Martinez, N. D., Hawkins, B. A., Dawah, H. A., Feifarek, B. P. (1999): Effects of sampling effort on characterization of food-web structure. - Ecology 80: 1044-1055.

[39] May, R. M. (1973): Stability and Complexity in Model Ecosystems. - University Press, Princeton.

[40] McCann, K. S., Hastings, A. (1997): Re-evaluating the omnivory-stability relationship in food webs. - Proceedings of the Royal Society of London 264: 1249-1254.

[41] McCann, K. S., Hastings, A., Huxel, G. R. (1998): Weak trophic interactions and the balance of nature. - Nature 395: 794-798.

[42] McCann, K. S. (2000): The diversity-stability debate. - Nature 405: 228-233.

[43] McCann, K. S. (2012): Mathematical Ecology. - University Press, Oxford. 
[44] McDonald-Madden, E., Sabbadin, R., Game, E. T., Baxter, P. W. J., Chadès, I., Possingham, H. P. (2016): Using food-web theory to conserve ecosystems. - Nature Communications 7: 10245. doi: 10.1038/ncomms10245.

[45] Melian, C. J., Bascompte, J., Jordano, P. (2005): Spatial structure and dynamics in a marine food web. - Aquatic Food Webs 1: 19-24.

[46] Mikola, J., Setälä, H. (1998): No evidence of trophic cascades in an experimental microbial-based soil food web. - Ecology 79: 153-164.

[47] Montoya, J. M., Pimm, S. L., Sole, R. V. (2006): Ecological networks and their fragility. - Nature 442: 259-264.

[48] Mougi, A., Kondoh, M. (2016): Food-web complexity, meta-community complexity and community stability. - Scientific Reports 6: 24478. doi: 10.1038/srep24478.

[49] Neutel, A. M., Heesterbeek, J. A., De Ruiter, P. C. (2002): Stability in real food webs: weak links in long loops. - Science 296: 1120-1123.

[50] Persson, L. (1999): Trophic cascades: abiding heterogeneity and the trophic level concept at the end of the road. - Oikos 85: 385-397.

[51] Pimm, S. L. (1982): Food webs. - Chapman and hall, New York.

[52] Pinnegar, J. K., Blanchard, J. L., Mackinson, S., Scott, R. D., Duplisea, D. E. (2005): Aggregation and removal of weak-links in food-web models: system stability and recovery from disturbance. - Ecological Modelling 184: 229-248.

[53] Polis, G. A. (1988): Exploitation competition and the evolution of interference, cannibalism, and intraguild predation in age/size-structured populations. - In: Sizestructured populations. Springer Berlin, Heidelberg.

[54] Polis, G. A. (1991): Complex trophic interactions in deserts: an empirical critique of food-web theory. - American Naturalist 138: 123-155.

[55] Polis, G. A., Strong, D. R. (1996): Food web complexity and community dynamics. American Naturalist 147: 813-846.

[56] Polis, G. A. (1999): Why are parts of the world green? Multiple factors control productivity and the distribution of biomass. - Oikos 86: 3-15.

[57] Power, E. M. (1992): Top-down and bottom-up forces in food webs: do plants have primacy. - Ecology 73: 733-746.

[58] Riede, J. O., Rall, B. C., Banasek-Richter, C., Navarrete, S. A., Wieters, E. A., Emmerson, M. C., Jacob, U., Brose, U. (2010): Scaling of food-web properties with diversity and complexity across ecosystems. - Advances in Ecological Research 42: 139-170.

[59] Romanuk, T. N., Zhou, Y., Valdovinos, F. S., Martinez, N. D. (2017): Robustness tradeoffs in model food webs: invasion probability decreases while invasion consequences increase with connectance. - Advances in Ecological Research 56: 263-291.

[60] Rooney, N., McCann, K. S. (2012): Integrating food web diversity, structure and stability. - Trends in Ecology \& Evolution 27: 40-46.

[61] Rossi, L., di Lascio, A., Carlino, P., Calizza, E., Costantini, M. L. (2015): Predator and detritivore niche width helps to explain biocomplexity of experimental detritus-based food webs in four aquatic and terrestrial ecosystems. - Ecological Complexity 23: 14-24.

[62] Schmid-Araya, J. M., Hildrew, A. G., Robertson, A., Schmid, P. E., Winterbottom, J. (2002): The importance of meiofauna in food webs: evidence from an acid stream. Ecology 83: 1271-1285.

[63] Shurin, J. B., Daniel, S., Gruner, D. S., Hillebrand, H. (2006): All wet or dried up? Real differences between aquatic and terrestrial food webs. - Proceedings of the Royal Society of London 273: 1-9.

[64] Strong, D. R. (1988): Food web theory: a ladder for picking strawberries? - Ecology 69: 1647-1676.

[65] Strong, D. R. (1992): Are trophic cascades all wet? Differentiation and donor control in speciose ecosystems. - Ecology 73: 747-754.

[66] Sugihara, G. K., Schoenly, K., Trombla, A. (1989): Scale invariance in food web properties. - Science 245: 48-52. 
[67] Thompson, R. M., Dunne, J. A., Woodward, G. (2012a): Freshwater food webs: towards a more fundamental understanding of biodiversity and community dynamics. Freshwater Biology 57: 1329-1341.

[68] Thompson, S. A., Sydeman, W. J., Santora, J. A., Black, B. A., Suryan, R. M., Calambokidis, J., Peterson, W. T., Bograd, S. J. (2012b): Linking predators to seasonality of upwelling: Using food web indicators and analysis to infer trophic connections. Progress in Oceanography 101: 106-120.

[69] Tylianakis, J. M., Laliberté, E., Nielsen, A., Bascompte, J. (2010): Conservation of species interaction networks. - Biological Conservation 143: 2270-2279.

[70] Van Altena, C., Hemerik, L., De Ruiter, P. C. (2016): Food web stability and weighted connectance: the complexity-stability debate revisited. - Theoretical Ecology 9: 49-58.

[71] Vermaat, J. E., Dunne, J. A., Gilbert, A. J. (2009): Major dimensions in food-web structure properties. - Ecology 90: 278-82.

[72] Williams, R. J., Martinez, N. D. (2000): Simple rules yield complex food webs. - Nature 404: 180-183.

[73] Worm, B., Duffy, J. E. (2003): Biodiversity, productivity and stability in real food webs. - Trends in Ecology \& Evolution 18: 628-632.

[74] Zhao, L., Zhang, H., O'Gorman, E. J., Tian, W., Ma, A., Moore, J. C., Stuart, R., Borrett, S. R., Woodward, G. (2016): Weighting and indirect effects identify keystone species in food webs. - Ecological Letters 19: 1032-1040. 